\title{
Management innovation and core competitive advantages of SMEs
}

\author{
WANG Wan-xun ${ }^{1}$, ZHAO Jie ${ }^{2}$, CHEN Hao-wen ${ }^{2}$ \\ (1. Xi'an Tobacco, Xi'an 710000, China; 2. School of Management, Xi'an Jiaotong University, Xi'an 710049, China)
}

\begin{abstract}
The paper first introduces the concept of core competence. Based on that, it proposes that small and medium enterprises (SMEs) should actively implement management innovation and describes the contents of management innovation. The conclusion is that SMEs should build the core competitive advantages through management innovation, in order to achieve better performance in the fierce market competition.
\end{abstract}

Key words: management innovation; SMEs; core competitive advantages

Due to China's rapid economic development, plenty of SMEs have made remarkable achievements and become an important part of Chinese economy. The quantity and sales are both showing continued growth trend. However, while recognizing the great achievements of SMEs, there are still some serious problems that must be noted apart from their great development. For a long time, a large number of SMEs rush into labor-intensive industries, which belong to the extensive economic model. Relying on the low-cost labor advantage, some processing and trade enterprises lies in coastal areas, form the export-dependent growth model. Huge trade surplus has brought rich and generous foreign exchange earnings, which are driving the economic development in the region in a certain period. But such mode has a serious shortage of development potential, and the lack of core competitiveness makes enterprises only occupy the low-end market. Therefore the increase space is limited. Particularly in the current economic crisis, the SMEs have been facing difficulties of survival, and the urgent problem is how to change and how to develop. Based on these problems, this paper aims to explore how to improve the management capacity of SMEs, in order to obtain the core competitive advantages.

\section{Core competence}

The concept of core competence was first proposed by Prahalad and Hamel (1990) in "The core competence of the corporation", which published in a respected journal called Harvard Business Review. According to Gary Hamel and CK Prahalad (1990), Compared to the corporations external environment, their own quality, the cultivation and accumulation of internal resources play a decisive role for companies to obtain a competitive advantage, and the core competence is the guarantee to ensure the development of enterprise in the future” (C. K. Prahalad \& Gary Hamel, 1990). Therefore, the core competence is an internal factor, which originates from high efficient management capabilities.

Other scholars have developed the concept of core competencies, and formed several different points of view. Many scholars believe that the core competence is a combined capacity, including a variety of contents, and emphasizing the utilization of resources to create value. Core competence should include the organization's

WANG Wan-xun, master, director general of Xi'an Tobacco, Xi'an Tobacco; research field: corporate management.

ZHAO Jie, Ph.D., School of Management, Xi'an Jiaotong University; research fields: strategic management and innovation.

CHEN Hao-wen, Ph.D., School of Management, Xi'an Jiaotong University; research fields: strategic management and innovation. 
unique human resources, material resources and organizational and coordination capacity (Duane Helleloid \& Bornard Simonin, 1994). Bogner and Thomas (1994) argued that the core competence is enterprises' unique skills and better perception to achieve the highest customer satisfaction when compared with the competitors, and this perception includes the tacit knowledge and the corporation's value (W. C. Bogner \& H. Thomas, 1994). As a conclusion, they emphasized that the core competence should include skills, knowledges and values etc. Thus, how to make efficient utilization of resources to establish a unique competitive advantage, especially the tacit competitive advantage, is an important issue about the concept of core competence.

\section{Management innovation}

According to dynamic capabilities theory, Martin (2000) pointed out that the competitive advantage exists in the enterprise's organization and management process, which are determined by the exclusive asset configuration and the evolution path of corporation. Based on this, management innovation is defined as how to make better use of companies' resources to conduct more effective management. The general problems in Chinese SMEs are non-normative and unscientific management. Meanwhile, the SMEs are devoid of brand awareness and ignore the value of good brand image as an intangible asset. Therefore, management innovation primarily refers to the establishment of management and brand advantages.

\subsection{Management advantage}

Management is an immanent mechanism. Although it doesn't have a direct and quantifiable impact on the manufacture and operation, actually, it has a long-term effect on the enterprise's survival and development in all aspects. It particularly does in the corporations without production and processing departments. Management advantage can be measured by personnel quality and internal control. A good quality of personnel is the base of efficient operation of the enterprise. Meanwhile, the strict scientific internal control system is the guarantee of standardized operation.

Personnel quality can be measured by education level of management team, average education level of employees, the number of professionals, the number of technological employees and staff. The enterprise should pay attention to the introduction and cultivation of high-quality personnel. The leaders with high education have relatively high cultural and knowledge quality, thus they will lead the company to establish an advanced concept and make the right decision. Employees with a high education level, especially professional and technical personnel, can bring in enormous research and development capabilities, and consequently help the enterprise gain a dominant place in a changing market. Good staff structure makes the enterprise form scientific organizational structure, and results in higher efficiency.

Internal control can be measured through the rate of employees' complaint, the rate of basic satisfaction level, the rate of passed random inspection, the rate of dealing with employee comments and discipline, conducting the enterprises to establish strict and scientific internal control system. The rate of employees' complaint and the rate of basic satisfaction level reflect the attitude and service quality of higher authorities. Then promoting them can improve the service quality and elevate the service level. The rate of passed random inspection and discipline reflect the attitude of employees and the restraints of the institution, then promote employees to work harder. So the institution will be enacted and implemented. Rate of dealing with employee comments reflects the acceptance of the comments of staff, then promote constructing extensive acceptance of opinions and forming humbly accepting criticism atmosphere.

Based on the definition above, management advantage should include the following specific aspects.

2.1.1 Quality of personnel 


\section{(1) Education level of management team}

Indicator description: Education level of management team reflects the basic quality of the management team. The larger the indicator is, the higher quality of the management team is, which promotes the current's and future's better operation. This indicator can be measured by the ratio of highly educated management team members to overall management team members.

Formula: The rate of highly educated management team members $=$

$$
\frac{\text { The number of highly educated management team members }}{\text { The number of overall management team members }} \times 100 \%
$$

(2) Average education level of employees

Indicator description: Average education level of employees reflects the basic quality of the entire staff. The larger indicator is, the higher average quality of employees will have, which leads to a better performance currently in the future. This indicator can be measured by the ratio of highly educated employees to entire staff.

Formula: The rate of highly educated employees =

$$
\frac{\text { The number of highly educated employees }}{\text { The number of entire staff }} \times 100 \%
$$

(3) Number of professionals

Indicator description: Professionals are the core power of an enterprise. The ratio of professionals to entire staff reflects the degree of personnel centrality. The larger the indicator is, the higher organizational efficiency and higher technology centrality will be.

Formula: The rate of professionals $=$

$$
\frac{\text { The number of professionals }}{\text { The number of entire staff }} \times 100 \%
$$

(4) Number of technological employees

Indicator description: Technological employees are the core power of technological innovation. The ratio of technological employees to entire staff reflects the R \& D (research and development) level of an enterprise. The larger indicator is, the higher R \& D level and greater innovation potential will be.

Formula: The rate of technological employees $=$

$$
\frac{\text { The number of technological employees }}{\text { The number of entire staff }} \times 100 \%
$$

(5) Staff structure

Indicator description: Staff structure is the distribution of the staff age, education, etc. It reflects the overall organizational structure and personnel distribution of an enterprise. This indicator is measured by the ratios of certain kinds of employees to entire staff, for example, the ratio of employees under 40 to entire staff.

\subsubsection{Internal control}

(1) The rate of employees' complaint

Indicator description: Employees' complaint reflects problems in the work of higher-level department or unit. The rate of employees' complaint refers to the ratio of the number of employees' complaint to the total number of work orders. It is a negative indicator. The larger indicator is, the more problems will have to be solved in the enterprise's management.

Formula: The rate of employee complaints=

$$
\frac{\text { The number of employee complaints }}{\text { The total number of work orders }} \times 100 \%
$$


(2) The rate of basic satisfaction level

Indicator description: Rate of basic satisfaction level is the degree of satisfaction of basic units to higher-level department's management and service. It reflects the management level and sense of service of higher-level functions. The larger the indicator, the better the management and service of higher-level functions.

(3)The rate of passed random inspection

Indicator description: The rate of passed random inspection is the ratio of passed random inspection to overall random inspection, which is about a certain work, carried out by superior to subordinate or evaluation sector to other departments. This indicator reflects the work level of various functions. The larger the indicator is, the higher work level of various functions will be.

Formula: The rate of passed random inspection=

$$
\frac{\text { The number of passed random inspection }}{\text { The number of overall random inspection }} \times 100 \%
$$

(4) The rate of dealing with employee comments

Indicator description: Rate of dealing with employee comments refers to the ratio of responded and disposed employee comments to overall employee comments. This indicator reflects the sense and intensity of the organization's self-management. The larger the indicator is, the stronger sense and greater intensity of organization's self-management will be.

Formula: The rate of dealing with employee comments =

$$
\frac{\text { The number of disposed employee comments }}{\text { The number of overall employee comments }} \times 100 \%
$$

(5) Discipline

Indicator description: Discipline reflects the normative level of the enterprise's system and the quality of staff. It can intuitively show the management level of the enterprise. This indicator is measured by the ratios of certain kinds of passed random inspection, for example, the ratio of present employees to overall employees who are required to be present in an activity.

\subsection{Brand advantage}

Brand advantage mainly comes from three aspects, the external service capability, the ability to integrate resources and the internal service capability. External service capability can be measured by value of intangible assets and customer satisfaction. Professionally-evaluated value of intangible assets reflects the company's brand value and customer satisfaction reflects the recognition of corporation from the market, which can conduct the corporation to focus on market response and then continuously improve service quality to meet customers' needs. Ability to integrate resources can be measured by the relationships with upstream and downstream businesses, which can conduct corporation to establish a good relationship with suppliers, and run stable and efficient channels and obtain the bargaining power in the relationships both with upstream and downstream enterprises, thus enable the business to be more autonomous and flexible. Internal service capacity can be measured by employer's image. A good image of the employer is the guarantee to maintain the incumbent employees, to attract new excellent staff, and to encourage the employees to work with passion, as well as creativity.

Based on the above, brand advantages specifically include the following aspects:

\subsubsection{External service capability}

(1) Value of intangible assets

Indicator description: Value of intangible assets is the value of the enterprise's brand image, goodwill and so 
on. It needs a professional assessment. The size of the value of intangible assets reflects the tacit competitiveness of the enterprises. The larger value of intangible assets, the greater the tacit competitiveness of the enterprises.

(2) Customer satisfaction

Indicator description: Customer satisfaction is the degree of customers' satisfaction to the enterprise's quality of product or service, as well as the recognition of the brand. Customer satisfaction reflects the market impression of the enterprise. The higher customer satisfaction is, the stronger market maintaining and expanding ability of the enterprise will have.

\subsubsection{Ability to integrate resources}

(1) Relationships with upstream business

Indicator description: Relationships with upstream business is a very important issue in the enterprise's operation. It reflects the stability and security of the supply chain. The more close relationships with upstream business as well as the more leading role and bargaining power are, the more reliable supply chain and greater operation freedom of the enterprise will have.

(2) Relationships with downstream business

Indicator description: Relationships with downstream business reflect the stability and integrity of the sales channels. It relates to the company's product and service output and income to be obtained. The more close relationships with downstream business as well as the more leading role and bargaining power are, the more reliable channel and secure income of the enterprise.

\subsubsection{Internal service capacity}

Internal service capacity is measured by the term of employer's image.

Indicator description: Employer's image reflects the attractiveness and appeal of the enterprise to talents from the staff and applicants. Enterprise with a good employer's image indicates the strong maintaining and attracting capacity to talent, which means a good foundation and source for development.

\section{Conclusion}

At present, China's economy is undergoing restructuring, transforming from labor-intensive to technology-intensive. How to build core competitive advantages in the transformational time is an important issue which matters with SMEs' survival and development. Now SMEs are struggling under the severe economic crisis. So how to make full use of resources to build up their core competitive advantages, turn crises into opportunities, and seek survival and development, are problems which must be solved. According to core competence theory, SMEs should actively implement management innovation, and change the lagging concepts and management patterns to improve management capacity and develop their own brands to promote the extensive economy transformation to intensive economy, then to achieve better performance in the intensive competitive market in the future.

\section{References:}

C. K. Prahalad \&Gary, Hamel. (1990, May-June). The core competence of the corporation. Harvard Business Review.

D. Helleoid \& B. Simionin. (1994). Organizational learning and a firm's core competence. The Strategic Management Society.

W. C. Bogner \& H. Thomas. (1994). Core competence and competitive advantage: A model and illustrative evidence from the pharmaceutical industry. The Strategic Management Society.

Kathleen, M. Eisenhardt \& Jeffrey, A. Martin. (2000). Dynamic capabilities: What are they? Strategic Management Journal, 21, 1105-1121. 